\title{
Stanley J. Korsmeyer
}

$T_{1}$

he world of biomedical science, and indeed the world at large, lost a beloved friend and stellar leader when Stanley J. Korsmeyer died on March 31, 2005, at the age of 54. Stan, a world-renowned physician-scientist, succumbed after a valiant battle with metastatic lung cancer. He had never been a smoker.

For those of us fortunate enough to have known and befriended Stan Korsmeyer as a youth, it was no surprise that his life and career would be marked by both phenomenal success as a scientist and, at the same time, an uncommon ability to earn the affection of those whose lives he touched. Stan grew up on a livestock farm in west central Illinois, where he learned from his parents, Willard and Carnell, and their family the virtues of humility, honesty, hard work, and a generosity of spirit that would be his trademark. Whether it was showing grand champion Hampshire hogs at the Illinois State Fair, playing first trombone in the county honor band, or carrying out groundbreaking research on the molecular basis for cancer, Stan was always focused, insightful, and brilliant on the one hand yet absolutely genuine, collegial, and very quick with kindness and a warm smile on the other.

Stan attended the University of Illinois, where his appetite for science was first whetted. As a medical student at the University of Illinois in Chicago, he enjoyed the mentorship of Paul Heller, who recognized Stan's potential and served as an important role model. While still a medical student, Stan did a visiting research project with Robert Strickland and Ralph Williams, which led to a first-authored article in the New England Journal of Medicine demonstrating lymphocytotoxic antibodies in inflammatory bowel disease. It was clear even then that he was destined for greatness.

After completing his medical residency at the University of California at San Francisco, Stan was recruited to the NIH with a postdoctoral fellowship by Tom Waldmann. In collaborative studies with Phil Leder's laboratory, the landmark discovery of a hierarchy of immunoglobulin gene rearrangements in acute lymphoid leukemia was made. These and follow-up studies by Korsmeyer and his colleagues established immunoglobulin gene rearrangements as unique clonal markers of lymphoid neoplasms.

Stan stayed on at the NIH after his fellowship ended and pursued the cloning of the breakpoint of the $t(14 ; 18)$ chromosomal translocation found in follicular B cell lymphomas. This line of investigation was to lead to his most celebrated scientific discovery and would remain the central focus of his scientific career. His work showing overexpression of the immunoglobulin gene-breakpoint cluster $2(\mathrm{Bcl}-2)$ gene in mature B cell lymphomas pointed to its potentially critical role in neoplasia.

After moving to Washington University School of Medicine, where he would even-

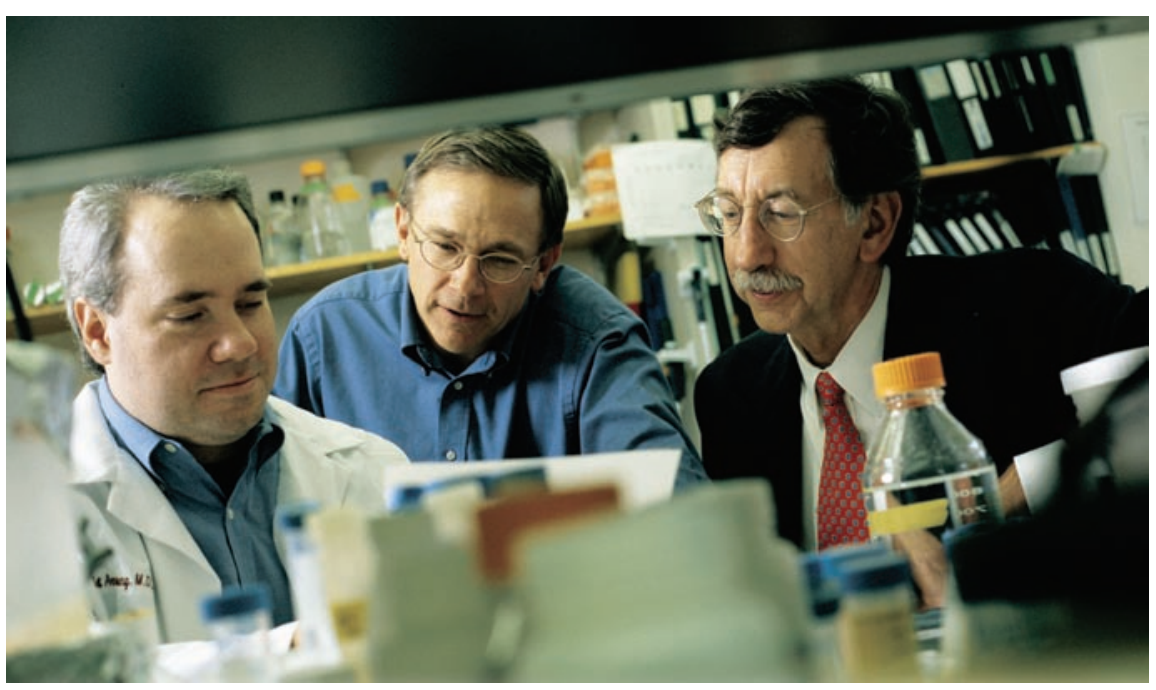

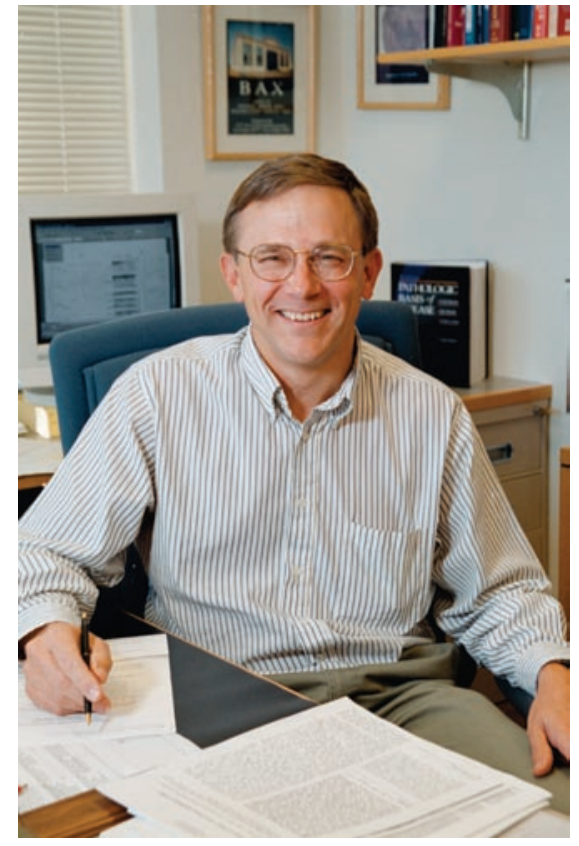

tually become the director of Molecular Oncology and an investigator in the Howard Hughes Institute, Stan's laboratory pursued the work on the $t(14 ; 18)$ breakpoint cluster gene. His group demonstrated that overexpression of the $\mathrm{Bcl}-2$ fusion gene in transgenic mice caused follicular center lymphoid hyperplasia. The remarkable and paradigm-changing finding in these studies was that the hyperplasia was due not to exaggerated or uncontrolled cell growth but to loss of normal programmed cell death, or apoptosis. Thus, these studies resulted in the identification of an entirely new class of oncogene that interferes with normal apoptosis. A series of studies in the Korsmeyer laboratory characterized the antiapoptotic Bcl-2 gene product as well as many of the related interaction partner proteins that control normal apoptosis. This family of regulators of apoptosis is now studied in nearly all areas of human biology.

In 1998, Stan was recruited to the Dana Farber Cancer Institute at Harvard Medical School. There, his laboratory continued to publish groundbreaking work on the mechanisms of apoptosis and its role in cancer and immune cell development, and he provided much admired leadership at the institute. Among the most recent work from his laboratory was the dem- 


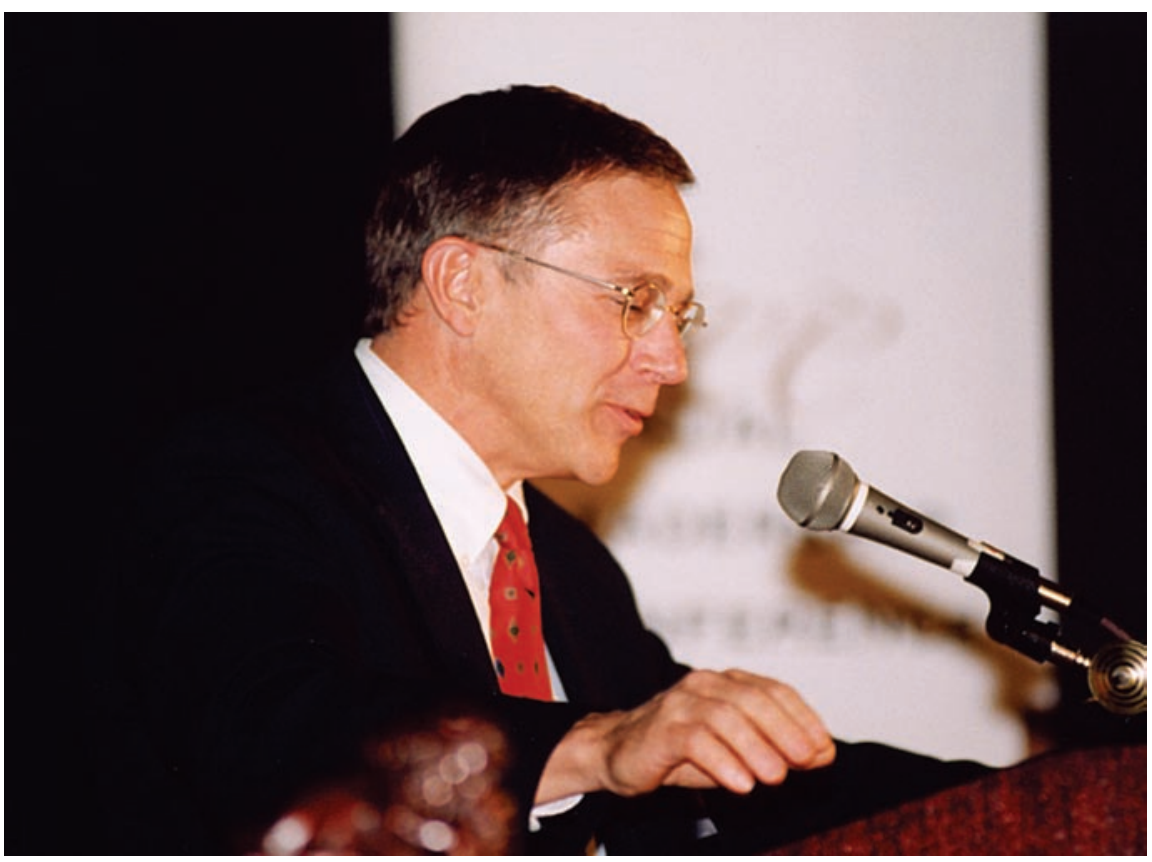

onstration that a stapled peptide could successfully inhibit interactions between $\mathrm{Bcl}-2$ protein family members and thereby disrupt their antiapoptotic activity. This work set the stage for potential targeted therapy of the many types of cancer now known to harbor defective apoptosis control mechanisms.

Stan Korsmeyer's seminal contributions to the understanding of the role of apoptosis in cancer resulted in many notable honors. These included election to the National Academy of Sciences, as well as such prestigious awards as the General Motors Foun- dation Mott Prize, the Pezcoller Foundation-AACR International Award for Cancer Research, the Bristol-Myers Squibb Award for Distinguished Achievement in Cancer American Society of Hematology, among many others.

Although Stan's professional accomplishments will have an enduring impact disease, it is his personal attributes that will be most fondly remembered by all those who knew him. As mentor to his trainees, many of whom are now successResearch, and the Stratton Medal of the on medical research and the treatment of ful faculty researchers themselves, he was always concerned about their individual development and success. Stan brought out the best in those whom he mentored and was an inspiring role model to future generations of physician-scientists. This same generosity of spirit and kindness was extended to all whom Stan encountered, but to none more than his own family. It was evident that Stan took greater pride in his wife, Susan, and his sons, Jason and Evan, than in any of his myriad outstanding professional achievements. His happiest moments were shared with his family and friends enjoying the simple pleasures of life, sharing the virtues he steadfastly carried with him from his roots in rural Illinois.

While contemplating the untimely death of such a remarkable colleague must leave us profoundly saddened, we should be reminded that Stan always possessed a great optimism in addition to his wonderful sense of humor and zest for life. He surely would want us all to share and carry on with those qualities. At times of particular joy and satisfaction, Stan often liked to say, "It doesn't get any better than this!" So, too, it can be said of his life as a physician-scientist, and even more so of him as a warm and generous human being: It simply didn't get any better than Stan Korsmeyer.

\section{Gordon D. Ginder}

Massey Cancer Center, Virginia Commonwealth University Health System, Richmond, Virginia, USA.gdginder@hsc.vcu.edu. 